\title{
Impact of using debates in a pharmacoeconomic course on students' self-reported perceptions of skills acquired
}

\author{
Sinaa Alaqeel, Ahmad Alghamdi, Bander Balkhi, Saja Almazrou, Shiekha Alaujan
}

Clinical Pharmacy Department, College of Pharmacy, King Saud University, Riyadh, Saudi Arabia

\author{
Keywords \\ Active learning \\ Debate \\ Pharmacoeconomics \\ Student perceptions
}

\author{
Correspondence \\ Sinaa Alaqeel \\ Clinical Pharmacy Department \\ College of Pharmacy \\ King Saud University \\ Riyadh 14511 \\ Saudi Arabia \\ salageel@ksu.edu.sa
}

\begin{abstract}
Objective: To explore the impact of debates on students' perceptions of their (i) ability to read and critically appraise pharmacoeconomic literature and (ii) confidence in synthesising evidence, reaching a decision, and communicating it effectively. Methods: 77 pharmacoeconomics course students participated in a debate exercise: one team for adding a medication to a formulary and the other against adding. The self-reported perceptions of skills acquired were evaluated via pre- and post-debate questionnaires. Results: 48 participants completed the pre- and post-debate questionnaires, and 60 completed the perceptions toward the debate activity questionnaire. The number of students who rated their ability to meet course learning objectives as excellent increased significantly after the debate. Also, the students' perceptions of their confidence in making a decision, critically analysing evidence, and communicating their arguments improved after the debate exercise. Conclusions: The debate approach is an effective teaching method that can improve students' perceptions of skills acquired.
\end{abstract}

\section{Introduction}

The Accreditation Council for Pharmacy Education (ACPE) is the national agency that accredits professional degree programmes in pharmacy in the United States of America and offers international stakeholders guidance on quality assurance and advancement of pharmacy education (ACPE, 2015). One of ACPE's accreditation standards and key elements for the professional programme in pharmacy leading to the doctor of pharmacy degree is specifying special emphasis on 'active learning pedagogy, content integration, knowledge acquisition, skill development, and the application of knowledge and skills to therapeutic decision-making' (ACPE, Standard 10) (ACPE, 2015).

Active learning is defined as any instructional method that actively engages students in their learning process (Prince, 2004). Participating in a debate is an example of developing active learning skills. Debate refers to the process of considering multiple viewpoints and arriving at a judgment, and its application ranges from an individual using debate to make a decision in his or her own mind to an individual or group using debate to convince others to agree with them' (Kennedy, 2007).

The literature describes the use of debates in pharmacy courses such pharmacokinetics (Erstad \& Murphy, 1994), critical care (Hawkins, Fulford, \& Phan, 2019), antimicrobial stewardship (McGee, Pius, \& Mukherjee, 2019), pharmacotherapy (Charrois \& Appleton, 2013), infectious disease therapeutics (Viswesh, Yang, \& Gupta, 2018), ethics (Hanna et al., 2014), immunisations (Blackmer, Diez, \& Klein, 2014), ambulatory care (Moore et al., 2015), selfcare (Lampkin et al., 2015), and advanced pharmacy practice experience (Dy-Boarman et al., 2018). The findings of these studies suggest that engaging in debate activities ultimately helped students improve their self-reported perceptions of abilities to evaluate the literature; develop 
evidence-based clinical decisions, reason, and structured arguments; think critically; and communicate information effectively. To effectively use pharmacoeconomic evidence in the decision-making process, pharmacists are ought to be able to use critical thinking to construct, identify, and evaluate relevant arguments. Therefore, the use of debate activity lends itself to the teaching of pharmacoeconomics. Pharmacy literature reports little or no use of the debate approach in teaching pharmacoeconomics. Moreover, in health sciences education, one paper (Khan et al., 2012) reported on dental students in an economic course debating 'Private health care is a better system than its government counterpart in caring for the health needs of a population'.

This study was aimed at determining how debates play a role in students' perceptions of the following: (i) ability to read and critically appraise pharmacoeconomic literature and (ii) confidence in synthesising evidence, reaching a decision, and communicating it effectively.

\section{Methods}

The pharmacoeconomic course is a compulsory two-credit course offered in the first semester during the fourth year of a five-year Doctor of Pharmacy (Pharm.D.) programme at the College of Pharmacy, King Saud University (KSU), in Riyadh, Saudi Arabia. One of the cognitive learning outcomes of the course is 'to critically appraise pharmacoeconomic and health outcomes literature'. To assess whether the objective is achieved by students, the traditional journal club presentation was used, where students are to present a pharmacoeconomic paper and support it through open discussion. However, recently, the instructors opted to switching to an alternative method, which is engaging students in debate exercises.

The College of Pharmacy at KSU has two campuses: one for female undergraduate students and the other for male students. Five faculty members are involved in this course: three in the female campus and two in the male campus. The instructors assigned two lectures (four hours in total) to teach students how to critically appraise pharmacoeconomic research articles using the Consolidated Health Economic Evaluation Reporting Standards (CHEERS) statement (Carswell, Moher, \& Greenberg, 2013).

Pharmacoeconomic evidence is applicable when a particular drug is under review by a pharmacy and a therapeutics committee concerning its addition or deletion from the hospital formulary. To simulate this, the debate assignment involves two teams of students debating the addition of a medication to the formulary: one team for adding and one against adding. The medication list was developed in consultation with various pharmacists working in hospitals. A sum of 77 enrolled students (51 female and 26 male) participated in this debate as part of their course assessment. In forming each team, the students were given freedom to self-select their members. The agreed number of students per team was five or six. Medications were randomly assigned to the opposing debate teams by the course instructors.

Eight weeks before the debate session, to ensure common ground for the debate, the instructors provided the teams with two different pharmacoeconomic studies on their target medication. The students were then required to identify other useful evidence independently. Instructors conducted a half-hour lecture to explain the debate format. To guide the students, the instructors identified relevant videos on YouTube relating to pharmacy students' debates and selected four of these videos with different pharmacy topics. These YouTube videos of pharmacy students debating, mostly demonstrating the debate process, were shared with students to give them some idea on what is expected to happen. The students were allowed to study them at the speed and time that is convenient to them.

All debate preparation was done outside of the class, but students were required to contact the instructors at least once during the semester for guidance and clarifications.

Each debate was allotted 40 minutes, using the format presented in Table I. The audience comprised of course instructors as well as non-participating students. The debates were graded by two course instructors using the same rubric used by Viswesh and authors (Viswesh et al., 2018) (Appendix 1), and an average score was calculated after the debate session. The students were provided in advance with the criteria and the rubric to help them anticipate what should take place during the debate. At the debate, students in the audience after each opposition round are given the chance to vote whether the medicine should be added to the formulary. The team who received $60.0 \%$ or more of the vote got a bonus of two points for that round. The final grade provided was a team grade for the whole presentation and not for an individual student. Finally, the debates accounted for $10.0 \%$ of the overall course grade.

The instructors assessed the outcome of this teaching technique using pre- and post-debate questionnaires. The questionnaires were developed on the basis of previous literature (Dy-Boarman et al., 2018; Viswesh et al., 2018) and underwent revisions by the instructors for face and 
Table I: The format of the debate

\begin{tabular}{|c|c|c|c|}
\hline Student & Segment of the debate & Purpose & Time (min) \\
\hline For: 1 & Opening statement & Present evidence for the for group & 5 \\
\hline \multirow[t]{2}{*}{ Against: 1} & Opening statement & Present evidence for the against group & 5 \\
\hline & & Break to prepare rebuttal & 2 \\
\hline For: 2 & Rebuttal & Identify flaws/weaknesses in the argument made by the against group & 5 \\
\hline Against: 2 & Rebuttal & Identify flaws/weaknesses in the argument made by the for group & 5 \\
\hline For: 3,4 & Cross-examination & Cross-examine the against group & 5 \\
\hline \multirow[t]{2}{*}{ Against: 3,4} & Cross-examination & Cross-examine the for group & 5 \\
\hline & & Break to prepare closing & 2 \\
\hline For: 5 & Closing statement & Summarise points and make final case for & 3 \\
\hline Against: 5 & Closing statement & Summarise points and make final case against & 3 \\
\hline
\end{tabular}

content validity. The pre- and post-debate questionnaires assessed students' perceptions of their level of ability to meet the pharmacoeconomic course learning objectives and their level of confidence in synthesising evidence, reaching a decision, and then communicating it effectively. In addition, the post-debate questionnaire used six statements and four open-ended questions to assess student perceptions of the debate activity. The pre-debate questionnaire was administered during the debate preparation, which was six weeks prior to the debates, and the post-debate questionnaire was distributed at the end of each debate. To ensure anonymity of students, the job of distributing, collecting, and matching of the preand post-debate questionnaires was done by a student representative (the class leader). Then, the instructors received the completed questionnaires free of any student information. The students had completed the post-debate questionnaires prior to the distribution of their assignment scores to avoid bias of scores impact on their perception of the experience.

Participation in the pre- and post-questionnaires was not compulsory for students, and no incentives were provided for participation. Only students who gave consent to participation completed questionnaires on their perceptions and opinions on the debate exercise.

Data represent findings from one cohort collected during the year 2019. The data were entered into and analysed via Microsoft Excel 2013. In addition to descriptive statistics, comparisons between the pre- and post-surveys were analysed with the paired samples Wilcoxon signedrank test with a priori alpha value of 0.05 for statistical significance. All statistical analyses were performed using SPSS software version 22.0 (IBM, Armonk, NY, USA).

The KSU Institutional Review Board reviewed and gave approval to this project.

\section{Results}

Overall, 58(75.3\%) and 60(77.9\%) students completed the pre-debate and post-debate, respectively. About $62.3 \%$ of the participating students $(n=48)$ were able to complete the pre- and post-debate questionnaires. The computed average student score on the debate exercise was 8.6 out of ten points.

$89.6 \%$ of students ( $n=52$ ) have not had any prior experience in or knowledge on how to critically evaluate research studies, and $70.6 \%(n=41)$ of them had never read a pharmacoeconomic paper before the course.

Tables II and III show the pre- and post-debate questionnaire results. The numbers show that after the debate, there were more students who rated their ability to meet course learning objectives as excellent (out of the eight learning objectives assessed, Table II presents only the four learning objectives that pertain to the debate activity). After the debate, students' perceptions of their confidence in debating have also improved significantly as fewer students were neutral in their answers and more students agreed strongly with the statements (Table III).

Table IV presents the students' opinions about the debate activity. Majority of the students believed that the debate 
Table II: Students perceived level of ability to meet the course learning objectives $(n=48)$

\begin{tabular}{|c|c|c|c|c|c|c|c|}
\hline The course learning objectives & Debate & (\%) Poor & $\begin{array}{l}\text { Below } \\
\text { average } \\
(\%)\end{array}$ & $\begin{array}{l}\text { Average } \\
\text { (\%) }\end{array}$ & $\begin{array}{l}\text { Above } \\
\text { (\%) average }\end{array}$ & $\begin{array}{l}\text { Excellent } \\
\text { (\%) }\end{array}$ & $p$ \\
\hline \multirow{2}{*}{$\begin{array}{l}\text { Compare and contrast cost effectiveness, } \\
\text { cost minimisation, cost utility, cost benefit, } \\
\text { and cost consequence }\end{array}$} & Pre & 31.2 & 27.1 & 33.3 & 6.3 & 2.1 & \multirow[b]{2}{*}{$0.001>$} \\
\hline & Post & 0 & 4.2 & 12.5 & 37.5 & 45.8 & \\
\hline $\begin{array}{l}\text { Identify, classify, and describe controversies } \\
\text { related to identifying costs, sources of costs }\end{array}$ & Pre & 37.5 & 27.1 & 27.1 & 8.3 & 0 & \multirow[b]{2}{*}{$0.001>$} \\
\hline $\begin{array}{l}\text { data, discounting benefits, and the need of } \\
\text { sensitivity analysis }\end{array}$ & Post & 0 & 6.3 & 27.1 & 47.9 & 22.9 & \\
\hline \multirow{3}{*}{$\begin{array}{l}\text { Compare and contrast the decision analytic } \\
\text { and statistical methods of modeling a disease } \\
\text { intervention } \\
\text { Critically evaluate pharmacoeconomics }\end{array}$} & Pre & 45.8 & 25.0 & 25.0 & 4.2 & 0 & \multirow[b]{2}{*}{$0.001>$} \\
\hline & Post & 0 & 6.3 & 37.5 & 39.6 & 16.6 & \\
\hline & Pre & 39.6 & 33.3 & 20.8 & 6.3 & 0 & \multirow[b]{2}{*}{$0.001>$} \\
\hline $\begin{array}{l}\text { literature including the strengths and } \\
\text { weaknesses of each study }\end{array}$ & Post & 0 & 2.1 & 29.2 & 45.8 & 22.9 & \\
\hline
\end{tabular}

Table III: Students' perceptions of their confidence in debating $(n=48)$

\begin{tabular}{|c|c|c|c|c|c|c|c|}
\hline Student's perception & Debate & $\begin{array}{l}\text { Strongly } \\
\text { disagree } \\
(\%)\end{array}$ & $\begin{array}{l}\text { Disagree } \\
\text { (\%) }\end{array}$ & $\begin{array}{l}\text { Neutral } \\
\text { (\%) }\end{array}$ & $\begin{array}{l}\text { Agree } \\
(\%)\end{array}$ & $\begin{array}{l}\text { Strongly } \\
\text { agree } \\
(\%)\end{array}$ & $p$ \\
\hline \multirow{2}{*}{$\begin{array}{l}\text { I am confident in my ability to utilise information from the } \\
\text { literature to develop a clear, concise rationale for why a } \\
\text { viewpoint is superior to an alternative. }\end{array}$} & Pre & 0 & 10.4 & 22.9 & 56.3 & 10.4 & \multirow[b]{2}{*}{0.003} \\
\hline & Post & 0 & 0 & 16.6 & 54.2 & 29.2 & \\
\hline \multirow{2}{*}{$\begin{array}{l}\text { I am confident in my ability to formulate an organised, } \\
\text { logical argument. }\end{array}$} & Pre & 0 & 6.3 & 31.2 & 50.0 & 12.5 & \multirow{2}{*}{0.001} \\
\hline & Post & 0 & 0 & 16.7 & 47.9 & 35.4 & \\
\hline \multirow{2}{*}{$\begin{array}{l}\text { I am confident in my ability to evaluate points from an } \\
\text { opposing argument and provide information to refute that } \\
\text { argument. }\end{array}$} & Pre & 0 & 6.3 & 35.4 & 43.8 & 14.6 & \multirow[b]{2}{*}{0.004} \\
\hline & Post & 0 & 0 & 16.6 & 54.2 & 29.2 & \\
\hline \multirow{2}{*}{$\begin{array}{l}\text { I am confident in my ability to anticipate opposing } \\
\text { argument and identify their limitations as it is presented. }\end{array}$} & Pre & 0 & 8.3 & 45.8 & 35.4 & 10.4 & \multirow{2}{*}{0.002} \\
\hline & Post & 0 & 2.1 & 18.7 & 52.1 & 27.1 & \\
\hline \multirow{2}{*}{$\begin{array}{l}\text { I am confident in my ability to answer questions defending } \\
\text { my argument. }\end{array}$} & Pre & 0 & 6.3 & 37.5 & 41.6 & 14.6 & \multirow{2}{*}{0.002} \\
\hline & Post & 0 & 0 & 20.8 & 43.8 & 35.4 & \\
\hline \multirow{2}{*}{$\begin{array}{l}\text { I am confident in my ability to develop challenging } \\
\text { questions probing an opposing argument. }\end{array}$} & Pre & 0 & 14.6 & 37.5 & 37.5 & 10.4 & \multirow{2}{*}{0.058} \\
\hline & Post & 0 & 2.1 & 41.6 & 37.5 & 18.7 & \\
\hline \multirow{2}{*}{$\begin{array}{l}\text { I am confident in my ability to convince an audience of my } \\
\text { viewpoint on a topic. }\end{array}$} & Pre & 0 & 12.5 & 33.3 & 37.5 & 16.7 & \multirow{2}{*}{0.002} \\
\hline & Post & 0 & 2.1 & 20.8 & 45.8 & 31.2 & \\
\hline \multirow{2}{*}{$\begin{array}{l}\text { I am confident in my ability to deliver a clear, organized, } \\
\text { and } \\
\text { engaging oral presentation within specified time } \\
\text { constraints. }\end{array}$} & Pre & 0 & 12.5 & 31.2 & 29.2 & 27.1 & \multirow{2}{*}{0.027} \\
\hline & Post & 0 & 2.1 & 20.8 & 43.8 & 33.3 & \\
\hline
\end{tabular}

exercise helped them improve their ability to evaluate pharmacoeconomic literature, discuss pharmacoeconomic results, and defend their opinions professionally.

When asked about the most enjoyable and fruitful part of the debate, students highlighted the post-debate discussion ( $n=18$ ), the chance to express their opinion, and the new learning experience. The factors that negatively affected the students' experience included the following: unclear instructions ( $n=9$; all male students), poor debate presentation by the opposite team $(n=9$; all male students), limited time allocated for presentation ( $\mathrm{n}$ = 8; all female students), the debating style of the opposite team $(n=4)$, the process of gathering supportive evidence $(n=4)$. Overall, the top suggestions for improving the excercise emphasised the need to provide helpful sample debates $(n=12)$ and more time for discussion and feedback $(n=7)$.

\section{Discussion}

This paper reports on a successful implementation of a debate exercise among pharmacoeconomics students. The participating students perceived the exercise to enhance their critical thinking and literature appraisal skills in pharmacoeconomics. Based on an analysis of the students' answers to pre- and post-debate questionnaires, improvements in self-reported confidence in making a 
Table IV: Students' perceptions toward the debate activity $(n=60)$

\begin{tabular}{|c|c|c|c|c|c|}
\hline Student's perception & $\begin{array}{l}\text { Strongly } \\
\text { disagree } \\
\mathrm{n}(\%)\end{array}$ & $\begin{array}{l}\text { Disagree } \\
\mathrm{n}(\%)\end{array}$ & $\begin{array}{l}\text { Neutral } \\
\text { n (\%) }\end{array}$ & $\begin{array}{l}\text { Agree } \\
\text { n (\%) }\end{array}$ & $\begin{array}{l}\text { Strongly } \\
\text { agree } \\
\mathrm{n}(\%)\end{array}$ \\
\hline $\begin{array}{l}\text { This debate enhanced my ability to critically evaluate pharmacoeconomics } \\
\text { literature. }\end{array}$ & 5.0 & 5.0 & 10.0 & 31.7 & 48.3 \\
\hline $\begin{array}{l}\text { This debate improved my ability to discuss the results of pharmacoeconomics } \\
\text { studies orally. }\end{array}$ & 5.0 & 5.0 & 8.3 & 41.7 & 40.0 \\
\hline This debate improved my ability to defend my opinions in a professional manner. & 5.0 & 5.0 & 16.7 & 45.0 & 30.0 \\
\hline $\begin{array}{l}\text { This debate helped me to understand the importance of both sides of a } \\
\text { controversial topic. }\end{array}$ & 5.0 & 6.7 & 16.7 & 28.3 & 43.3 \\
\hline $\begin{array}{l}\text { I found participation in the debate to be more valuable than traditional } \\
\text { presentation. }\end{array}$ & 5.0 & 11.7 & 10.0 & 28.3 & 45.0 \\
\hline Overall, I found participation in the debate to be a beneficial experience. & 8.3 & 1.7 & 8.3 & 23.3 & 58.3 \\
\hline
\end{tabular}

decision, critically analysing evidence, and communicating their arguments can be observed. The results in this study support other published studies on the effective use of the debate approach in pharmacy education (Blackmer et al., 2014; Charrois \& Appleton, 2013; Erstad \& Murphy, 1994; Hanna et al., 2014; Hawkins et al., 2019; Kennedy, 2007; Lampkin et al., 2015; McGee et al., 2019; Moore et al., 2015; Viswesh et al., 2018). However, the post-debate questionnaire also revealed a small percentage of students who did have lower scores on self-reported abilities. This could be attributed to response shift bias as the students became more aware of their deficiencies while preparing for the debate (Rascati et al., 2004).

The aim of this debate assignment is to engage students to proactively identify, critically examine, and synthesise evidence to reach their decision and communicate it effectively. This activity helped students reach the higher levels of cognitive skills which is a goal of all pharmacy curricula. Furthermore, the activity helps students anticipate challenges they will encounter in practice where real-life decisions need to be made despite challenges such as lack of evidence, weak or conflicting evidence, and tradeoffs between needs, and limited resources. The ACPE Standards require that graduates have the keen ability to evaluate scientific literature to advance population health and patient-centred care (Standard 1.1) and effectively communicate verbally and nonverbally when interacting with individuals, groups, and organisations (Standard 3.6) (ACPE, 2015). Such requirements align with the current debate activity educational goals; hence, this approach will be adopted as a part of the institution's pharmacoeconomic course.

Based on the comments by students on the activity, a few areas can be modified to improve future debates. The introduction of an element of written arguments and students will publish their written arguments on the university's Learning Management System. Samples of debates by course alumni will also be shared with the aim of explaining the debate process. Increased time allotted for discussion and feedback after each debate should also consider. And lastly, inviting clinical faculty and those involved in the pharmacy and therapeutics committee to observe the debate and participate in the discussion and feedback would contribute largely to the students' overall experience. In improving the assessment process of the students' performance, the quality of the debates and students' critical thinking skills could be measured by evaluating students' argument structures and types of informal reasoning using a method similar to that reported by Chorris and authors (Charrois \& Appleton, 2013). Moreover, concerning the debate exercise, students were not required to calculate the incremental cost effectiveness ratio using the gathered evidence, or conducting a decision analysis model as this was outside the scope of the current debate objectives. Cavanaugh aud authors (Cavanaugh, Buring, \& Cluxton, 2012) reported on an interesting experience of a collaborative decision analysis project implemented in the pharmacoeconomic course and formulary management module of the pharmacy practice skills development course. In that study, students used decision analysis techniques to make comparison assessments of newly approved drugs with the current standard of care. On the basis of all the accepted related information about the drug pair, each group made a decision on whether to add the requested drug to the formulary. The results were then used in a mock pharmacy and therapeutics committee meeting (Cavanaugh et al., 2012). This presents another way to improve student learning and could be explored in future research studies.

There are few challenges in maintaining this debate exercise must be considered. First, the instructors have to regularly change the medications list each year to ensure 
that questions remain pertinent and preventing sharing of information between different cohorts of students this however suggests additional load for instructors. Second, although the instructors emphasise the importance of distributing the responsibility evenly among group members, students' contributions to the group's overall performance may still remain unbalanced. This is a common problem in team-based learning activities. One way to minimise this issue is to encourage students to discuss problems with some group dynamics with the instructors. A peer grading system may also encourage equal contribution from all students.

There are two notable limitations to the study's findings. Firstly, the findings are based on students' perceptions of the debate activity. The use of such a subjective assessment method, however, to measure of impact of an institutions teaching technique may have introduced social desirability response bias and a false perception of improvement (Swindle, Baker, \& Auld, 2007). Secondly, the sample size used in this study is relatively small and only one cohort of students was assessed. The limitations of using subjective outcome measures and small sample sizes are discussed in previous similar literature (Blackmer et al., 2014; Hanna et al., 2014; Hawkins et al., 2019; McGee et al., 2014; Moore et al., 2015). Therefore, future research studies should aim to objectively assess the impact of debate activity on students' learning outcomes using an appropriate sample size. Furthermore, methodological triangulation (Walsh, 2013) by following the correct questionnaire survey with a focus group with students that allow in-depth understanding of the research findings is warranted.

\section{References}

Accreditation standards and key elements for the professional program in pharmacy leading to The doctor of pharmacy degree. (2015). Chicago, Illinois. Available from: https://www.acpeaccredit.org/

Blackmer, A.B., Diez, H.L., \& Klein, K.C. (2014). Design, implementation, and assessment of clinical debate as an active learning tool in two elective pharmacy courses: Immunizations and Pediatrics. Currents in Pharmacy Teaching and Learning, 6(2), 254-258.

Carswell, C., Moher, D., \& Greenberg, D. (2013). Consolidated Health Economic Evaluation Reporting Standards ( CHEERS ) statement, 1049(March), 1-6. https://doi.org/10.1136/ bmj.f1049

Cavanaugh, T.M., Buring, S., \& Cluxton, R. (2012). A pharmacoeconomics and formulary management collaborative project to teach decision analysis principles.
American Journal of Pharmaceutical Education, 76(6). https:// doi.org/10.5688/ajpe766115

Charrois, T.L., \& Appleton, M. (2013). Online debates to enhance critical thinking in pharmacotherapy. American Journal of Pharmaceutical Education, 77(8). https://doi.org/ 10.5688/ajpe778170

Dy-Boarman, E.A., Bryant, G.A., Herring, M.S., \& Foster, K.Y. (2018). Impact of debates on student perceptions and competency scores in the advanced pharmacy practice setting. Currents in Pharmacy Teaching and Learning, 10(1), 66-71. https://doi.org/10.1016/j.cptl.2017.09.011

Erstad, B.L., \& Murphy, J.E. (1994). Developing critical interaction skills in students - debating clinical pharmacokinetic controversies. American Journal of Pharmaceutical Education, 58(4), 440-445.

Hanna, L.A., Barry, J., Donnelly, R., Hughes, F., Jones, D., Laverty, G., Parsons, C., \& Ryan, C. (2014). Using debate to teach pharmacy students about ethical issues. American Journal of Pharmaceutical Education, 78(3). https://doi.org/10.5688/ ajpe78357

Hawkins, W.A., Fulford, M., \& Phan, S.V. (2019). Using debates as the primary pedagogy to teach critical care in a PharmD curriculum elective course. Currents in Pharmacy Teaching and Learning, 11(9), 943-948. https://doi.org/10.1016/ j.cptl.2019.05.010

Kennedy, R. (2007). In-class debates: Fertile ground for active learning and the cultivation of critical thinking and oral communication skills. International Journal of Teaching \& Learning in Higher Education, 19(2), 183-190.

Khan, S.A., Omar, H., Babar, M.G., \& Toh, C.G. (2012). Utilization of debate as an educational tool to learn health economics for dental students in Malaysia. Journal of Dental Education, 76(12), 1675-1683.

Lampkin, S.J., Collins, C., Danison, R., \& Lewis, M. (2015). Instructional design and assessment active learning through a debate series in a first-year pharmacy self-care course. American Journal of Pharmaceutical Education, 79(2).

McGee, E.U., Pius, M., \& Mukherjee, K. (2019). Assessment of structured classroom debate to teach an antimicrobial stewardship elective course. Currents in Pharmacy Teaching and Learning, (xxxx), 0-1. https://doi.org/10.1016/j.cptl.2019.11.016

Moore, K. G., Clements, J., Sease, J., \& Anderson, Z. (2015). The utility of clinical controversy debates in an ambulatory care elective. Currents in Pharmacy Teaching and Learning, 7(2), 239248. https://doi.org/10.1016/j.cptl.2014.11.020

Prince, M. (2004). Does Active Learning Work ? A Review of the Research. Journal of Engineering Education, 93(July), 223-231.

Rascati, K.L., Drummond, M.F., Annemans, L., \& Davey, P.G. (2004). Education in pharmacoeconomics: An international multidisciplinary view. PharmacoEconomics, 22(3), 139-147. https://doi.org/10.2165/00019053-200422030-00001

Swindle, S., Baker, S.S., \& Auld, G.W. (2007). Operation Frontline: assessment of longer-term curriculum effectiveness, evaluation 
strategies, and follow-up methods. Journal of Nutrition Education and Behavior, 39(4), 205-213. https://doi.org/10.1016/ j.jneb.2007.03.003

Viswesh, V., Yang, H., \& Gupta, V. (2018). Evaluation of a modified debate exercise adapted to the pedagogy of team-based learning. American Journal of Pharmaceutical Education, 82(4), 345-353. https://doi.org/10.5688/ajpe6278

Walsh, K. (2013). When I say ... triangulation, (March), 6550. https://doi.org/10.1111/medu.12241

\section{Appendices}

\section{Appendix 1}

Dear Evaluator,

Please grade the presenting team as a whole (not individual students) in their ability to perform each of the criteria below, by providing a corresponding number from 1 to 5 using the scale provided below.

\begin{tabular}{|l|l|}
\hline Content & Score \\
\hline $\begin{array}{l}\text { Identify and critically evaluate primary literature including } \\
\text { strengths/weaknesses }\end{array}$ & \\
\hline $\begin{array}{l}\text { Develop a concise, evidence-based, argument defending their } \\
\text { viewpoint }\end{array}$ & \\
\hline $\begin{array}{l}\text { Anticipate opposing arguments and successfully identify } \\
\text { limitations in them }\end{array}$ & \\
\hline $\begin{array}{l}\text { Effectively answer questions defending their argument and } \\
\text { Develop challenging questions probing an opposing argument }\end{array}$ & \\
\hline $\begin{array}{l}\text { Convince an audience with credibility and evidence-based } \\
\text { rationale (rather than just opinion) }\end{array}$ & \\
\hline Delivery & \\
\hline Maintain eye contact with audience & \\
\hline Speak clearly with enthusiasm and confidence & \\
\hline Give concise and well-organized presentations & \\
\hline Deliver all arguments with a high degree of professionalism & \\
\hline Complete presentations within allotted time & \\
\hline Overall assessment & \\
\hline Deliver an argument and presentation of overall high quality & \\
\hline
\end{tabular}

Score: Am J Pharm Educ. 2018;82(4):345-353

1 - Poor (did not achieve any objectives)

2-Below average

3 - Average (achieved minimum objectives)

4-Above average

5 - Excellent (impressive overall and achieved more than minimum objectives) 